\title{
CARACTERIZAÇÃO DE BACTÉRIAS EM NÓDULOS DE LEGUMINOSAS ARBÓREAS DE FRAGMENTOS DA FLORESTA OMBRÓFILA MISTA
}

\author{
Characterization of bacteria in nodules of arboreal legumes of fragments of the mixed ombrophila forest
}

\author{
Marithsa Maiara Marchetti1*; Julio Cesar Pires Santos²; Cesar Milton Baratto ${ }^{3}$
}

${ }^{1}$ Mestre em Ciência do Solo; Universidade do Estado de Santa Catarina - UDESC; email: marithsamai@gmail.com *Autor para correspondência

2Doutor em Solos e Nutrição de Plantas; Universidade do Estado de Santa Catarina - UDESC; bijagica@gmail.com 32Doutor em Biologia Celular e Molecular; Universidade do Oeste de Santa Catarina - UNOESC; cesar.baratto@unoesc.edu.br

\section{Artigo enviado em 23/03/2017, aceito em 01/09/2017 e publicado em 20/12/2017.}

Resumo - A fixação biológica do nitrogênio (FBN) envolve uma sucessão de processos que começam com a adaptação da bactéria à planta e culminam na fixação do nitrogênio atmosférico, sendo mediada por uma parcela dos procariotos que, apesar de relativamente pequena, apresenta alta diversidade morfológica, fisiológica, genética e filogenética. O estudo teve por objetivo a caracterização morfofisiológica e genética de bactérias fixadoras de nitrogênio nodulantes de sete leguminosas arbóreas florestais. Ao todo, foram obtidos 79 isolados no período do inverno e verão, nas espécies estudadas. Com base nas propriedades morfofisiológicas, os isolados foram classificados em oito grupos. Pela análise do DNA dos isolados após a amplificação com OPA-4 em RAPD, foi possível constatar um grau elevado de diversidade genética, com a obtenção de 19 grupos distintos e, pela amplificação por ERIC obteve-se 18 grupos, ambas com $90 \%$ de similaridade. As populações de rizóbios diferiram ainda pela técnica de PCR-RFLP do gene ribossomal 16S, com a digestão pela endonuclease de restrição Hinfl, e foram obtidos 54 grupos com $90 \%$ de similaridade, que poderiam indicar a ocorrência de espécies distintas dentro do gênero Burkholderia a qual prevaleceu no estudo. Os resultados indicam que a predominância do gênero Burkholderia ocorreu devido a versatilidade nutricional e adaptativa do gênero, caracterizando assim o elevado grau de polimorfismo e dominância no estudo.

Palavras-Chave - Caracterização morfofisiológica; Rizóbios; Caraterização genética; Burkholderia.

\begin{abstract}
Biological nitrogen fixation involves a series of processes beginning with the adaptation of the bacteria to the plant and terminate in fixation of atmospheric $\mathrm{N}_{2}$, being mediated by a portion of prokaryotes that, though relatively small, exhibits high morphological diversity, physiological, genetic and Phylogenetic. The study aimed to Morphophysiological and genetic characterization of nitrogen fixing bacteria nodulation in seven forest legume trees. In total, 79 isolates were obtained in winter and summer period, in the studied species. Based on the morphological and physiological properties, the isolates were classified into eight groups. For DNA analysis of isolated after amplification with OPA-4 RAPD, there has been a high degree of genetic diversity, obtaining 19 different groups, and for the amplification ERIC was obtained18 groups, both with $90 \%$ similarity. The populations of rhizobia differ even by PCR-RFLP of the $16 \mathrm{~S}$ ribosomal gene with the digestion by HinfI restriction endonuclease and were obtained 54 groups with $90 \%$ similarity, which could indicate the occurrence of different species within the genus Burkholderia the which prevailed in the study. Although there was a predominance genus Burkholderia, the results indicate that this predominance was due to nutritional and adaptive versatility of its kind, characterizing the high degree of polymorphism and dominance in the study.
\end{abstract}

Keywords - Morphophysiological characterization; Rhizobia; Genetic characterization; Burkholderia 


\section{INTRODUÇÃO}

A Floresta Ombrófila Mista (FOM) ocupa aproximadamente $31 \%$ do estado de Santa Catarina, sendo a maior de todas as florestas em cobertura no estado (VIBRANS et al., 2013). De acordo com Machado et al. (2009), é uma das tipologias vegetais da região Sul do Brasil com maior riqueza e diversidade de espécies. Possui uma estrutura complexa e há pouco conhecimento sobre os diversos tipos de comunidades que existem dentro de sua área de distribuição natural (NASCIMENTO et al., 2001).

A FOM destaca-se como maior região fitoecológica do estado de Santa Catarina, sendo que nos trabalhos desenvolvidos por MEYER et al. (2013), a família Fabaceae foi considerada a terceira maior em riqueza específica, apresentando 58 espécies e também segunda maior riqueza de componentes arbóreos na FOM, apresentando 37 espécies no estado. De acordo com Primieri et al (2013), a FOM foi alvo de intensa exploração madeireira e uma grande mudança no uso do solo foi configurada ao longo do tempo.

A Floresta Ombrófila Mista situada em Caçador/SC está sobre solos classificados como Nitossolo Bruno, compreendendo a solos minerais, não hidromórficos, com horizonte $\mathrm{B}$ textural, argila de atividade baixa, com fertilidade variável e baixa disponibilidade de fósforo. Estes solos ocorrem na Unidade de Relevo Planalto das Araucárias, normalmente em relevo ondulado e forte ondulado, sob vegetação de Savana e Floresta Ombrófila Mista. É caracterizado por invernos com geadas e verões com uma temperatura média de $22^{\circ} \mathrm{C}$ (CALDATO; LONGHI; FLOSS, 1999).

Esse bioma ocupa aproximadamente 1.194 hectares em Caçador-SC, possuindo em sua composição maior riqueza das famílias Myrtaceae, Lauraceae, Fabaceae, Flacourtiaceae, Asteraceae, Aquifoliaceae e Sapindaceae, que representa cerca de $52,8 \%$ do número total de espécies encontradas (HERRERA et al., 2009).

As leguminosas arbóreas nativas representam um potencial inexplorado, devido ao desconhecimento de suas características silviculturais, sua produtividade e, especialmente, sua habilidade em associar-se a bactérias fixadoras de nitrogênio. $O$ relevante interesse na utilização de espécies como ingá e mimosa decorre das ações para recuperação de áreas degradadas, da restauração florestal e, ou da recomposição de matas ciliares desses locais (GROSS, 2010).

Diversos processos bioquímicos são mediados por microrganismos no solo que desempenham assim um papel importante na ciclagem de nutrientes (MOREIRA et al.; 2010). As interações específicas entre plantas e microrganismos possuem um forte impacto sobre o funcionamento dos ecossistemas, e consequentemente nos ciclos biogeoquímicos, sendo que a disponibilidade dos nutrientes no solo está envolvida desde os seus diferentes arranjos químicos até a incorporação na biomassa microbiana (RINCÓN; GUTIÉRREZ, 2012).
De acordo com Moreira et al. (2010), os diazotróficos compreendem ampla gama de microrganismos procariotos, incluindo representantes de arquebactérias, cianobactérias, bactérias gram-positivas e gram-negativas que apresentam grande diversidade morfológica, fisiológica, genética e filogenética. Tal diversidade garante não só a resiliência dos processos de um determinado ecossistema, como também a ocorrência deste nos mais diferentes habitats terrestres.

De acordo com Moreira; Huising; Bignell (2010) existem oito gêneros de bactérias nodulíferas fixadoras de nitrogênio, sendo eles: Allorbizobium, Rhizobium, Sinorbizobium, Mesorbizobium, Bradbyrizobium, Azorbizobium, Cupriavidus e Burkholderia.

A engenharia genética como ferramenta para a identificação de microrganismos tem crescido cada vez mais, facilitando os processos de identificação. A taxonomia dos rizóbios tem se desenvolvido rapidamente e têm sido descritas muitas espécies e gêneros novos com a ajuda da engenharia genética presente nesses procariotos (ROCHA, 2007). Os ribossomos procarióticos consistem de três moléculas de RNA (5S, $16 \mathrm{~S}$ e $23 \mathrm{~S}$ ) de diferentes tamanhos e cerca de 50 proteínas ribossomais (STRALIOTTO; RUMJANEK, 1999). O estudo com rizóbios tem sido cada vez mais intenso, já que os mesmos possuem grande importância ecológica e econômica; no entanto a nodulação tem sido avaliada em uma pequena parte apenas das leguminosas, cerca de 10\% (MOREIRA, 2008).

Diante disso não existem dúvidas de que a ocorrência e diversidade dessas bactérias ainda precisa ser explorada. Neste contexto, este trabalho teve como objetivo isolar e caracterizar morfofisiologicamente e geneticamente as bactérias fixadoras de nitrogênio encontradas em nódulos presentes em espécies arbóreas de leguminosas da família Fabaceae, ocorrentes na Floresta Ombrófila Mista, no Estado de Santa Catarina e comparar técnicas para avaliação do grau de polimorfismo.

\section{MATERIAIS E MÉTODOS}

O estudo foi realizado na Floresta Ombrófila Mista da Reserva Florestal Embrapa/Epagri, localizada na cidade de Caçador, região centro-oeste do estado de Santa Catarina, durante duas estações do ano, inverno e primavera de 2014

\section{Identificação das Espécies Florestais}

O levantamento e seleção das espécies florestais de leguminosas arbóreas teve como embasamento o Inventário Florístico Florestal de Santa Catarina (MEYER et al. 2013), onde foram selecionadas sete espécies de porte arbóreo, demarcando-se cinco exemplares cada espécie para as avaliações. As espécies arbóreas selecionadas e identificadas para a pesquisa da ocorrência de bactérias noduliferas foram: Mimosa scabrella, Mimosa flocculosa (em 
plantio), Inga lentiscifolia, Inga sp, Machaerium brasiliense Machaerium stipitatum e Baubinia forficata. A ocorrência de bactérias em nódulos radiculares na Mimosa scabrella foi realizada em um sistema de plantio e um de ocorrência natural.

\section{Caracterização do Solo}

Para obter parâmetros químicos do solo e correlacionar com a ocorrência dos microrganismos presentes na área, foram feitas coletas de solo para cada uma das plantas amostradas, e posteriormente submetidos as análise físico-química ( $\mathrm{pH}$, macro e micronutrientes, CTC, matéria orgânica, argila) a metodologia foi seguida conforme descrito por Tedesco; et al. (1995).

\section{Coleta dos Nódulos}

A metodologia utilizada foi a descrita por Hungria (1994). A coleta dos nódulos radiculares foi realizada em cinco exemplares de cada espécie em dois períodos, sendo caracterizada como inverno (agosto/2014) e primavera (novembro/2014).

\section{Caracterização Morfológica dos Nódulos}

Para a caracterização dos nódulos, os mesmos foram classificados em determinados para aqueles que apresentavam morfologia sem ramificações e/ou esféricos e indeterminados para aqueles que possuíam ramificações e/ ou cilíndricos em sua estrutura, seguindo a ideia descrita por Maunoury et al. (2008).
Isolamento de Bactérias de Nódulos de Espécies Arbóreas

Para o isolamento dos microrganismos foi seguida a metodologia descrita por Hungria (1994).

\section{Caracterização Morfofisiológica dos Isolados Bacterianos}

Para a caracterização dos microrganismos realizou-se a avaliação morfofisiológica das culturas obtidas, sendo observadas as seguintes características descritas por Araújo (1994). Posteriormente as amostras encontradas nos nódulos das leguminosas arbóreas foram agrupadas e separadas nos possíveis gêneros conforme características relatadas por Moreira; Huising; Bignell (2010), como pode ser visualizado na tabela 1. Para garantir a manutenção dos isolados até sua caracterização molecular, procedeu-se a liofilização das bactérias.

\section{Extração do Material Genético}

Para a extração do material genético foi selecionado um isolado proveniente de cada grupo resultante no agrupamento com base nas suas características morfofisiológicas. As bactérias foram crescidas em meio com extrato de levedura, manitol, sais minerais (YM) líquido durante três dias a $28^{\circ} \mathrm{C}$, com posterior extração do material genético pelo método Marmur (1961) modificado, com a ressuspensão das bactérias em $0,60 \mathrm{ml}$ de solução FTA.

Tabela 01. Características morfofisiológicas dos gêneros de bactérias fixadoras de nitrogênio nodulantes.

\begin{tabular}{c|c|c|c|c|c|c|c|c|c}
\hline Genero & Transparência & Cor & Tamanho & Borda & Elevação & $\begin{array}{c}\text { Taxa de } \\
\text { crescimento }\end{array}$ & Forma & Muco & $\mathrm{pH}$ \\
\hline $\begin{array}{c}\text { Allorbizobium } \\
\text { Rhizobium } \\
\text { Sinorrbizobium }\end{array}$ & ST & A & $2-4 \mathrm{~mm}$ & L & CV & L & Ci & 3 & AD \\
\hline Mezorhizobium & ST & A & $2-4 \mathrm{~mm}$ & L & CV & L & Ci & 3 & AD \\
\hline Bradirhizobium & O & B & $1<$ & L & CV & L & P & 1 à 2 & BS \\
\hline Azorhizobium & O & C & $0,5 \mathrm{~mm}$ & L & CV & R à I & P & 1 & BS \\
\hline Cupriavidus & O & C & $0,5 \mathrm{~mm}$ & L & CV & I & P & 3 & BS \\
\hline Burkolderia & ST & A & $2-4 \mathrm{~mm}$ & L & CV & R & Ci & 3 & $\begin{array}{c}\text { AD / } \\
\text { BS }\end{array}$ \\
\hline
\end{tabular}

Fonte: MOREIRA; HUISING; BIGNELL, 2010.

Legenda: Transparência: ST - semitranslucidas; O - opacas; Cor: A - amarelada; B - branca; C - creme; Borda: L - lisa; R - rugosa; Elevação: Ac achatada; $\mathrm{Cp}$ - cupular; $\mathrm{Cv}$ - cônvexa; Taxa de crescimento: $\mathrm{R}$ - rápido (3 dias); I - intermediário (4 a 7 dias); L - lento (8 a 10 dias); Forma: Ci - circular; $\mathrm{P}$ - puntiforme; Muco: 1 - pouco; 2 - médio; 3 - muito; 4 - abundante; $\mathrm{pH}$ : AD - ácido; $\mathrm{N}$ - neutro; BS - básico;

\section{Técnicas Moleculares (RAPD-PCR; ERIC-PCR; RFLP)}

O material genético extraído foi submetido às análises de amplificação por polimorfismo de DNA amplificado por acaso (RAPD), amplificação de PCR com a utilização de oligonucleotídeos iniciadores que amplificam sequências repetidas (ERIC) e pela técnica de polimorfismo do tamanho de fragmentos de restrição (RFLP), seguindo a metodologia descrita por (BARATTO et al, 2012).

Para a técnica de RAPD, quatro oligonucleotídeos diferentes foram testadas em uma pequena amostra de 
isolados, a fim de selecionar o melhor iniciador para o estudo. Os oligonucleotídeos utilizados foram: P1254 (CCGCAGCCAA), OPB-17 (AGGGAACGAG), OPA-4 (AATCGGGCTG) e OPB-15 (CCAGGGTGTT).

A seleção da endonuclease de restrição a ser usada nos isolados obtidos, foi realizada por corrida em sílico pelo método descrito por Bernardi (2012) com o uso das endonucleases Hinf I, Alu I, Taq I, Rsa I e Hae III, e com o auxílio do programa de bioinformática Vector NTI Version 4.0; Para isso, sequências do gene ribossomal 16S de espécies dos gêneros Allorbizobium, Rhizobium, Sinorrbizorbium, Mezorbizobium, Burkbolderia, Azorbizobium, Cupriavidus e Bradhyrbizobium foram pesquisadas no GenBank; e armazenadas na memória do programa de bioinformática, procedendo assim a clivagem in silico com as endonucleases selecionas, obtendo um padrão de restrição para cada um dos gêneros com suas respectivas espécies. Com base na corrida in silico, foi selecionada a endonuclease HinfI para proceder os testes com os isolados.

$\mathrm{Na}$ análise estatística foram utilizados os programas Free Tree - prerelease version (version 0.9.1.50) para calcular o índice de similaridade de Jaccard com o método UPGMA entre os isolados com base nas análises genéticas, e o programa TreeViem (Win32) version 1.6.6 para expressar os dados em dendrogramas.

\section{RESULTADOS E DISCUSSÃO}

Entre as sete espécies de leguminosas estudadas, pode-se observar maior distribuição de Mimosa scabrella (natural) e de Baubinia forficata, sendo observadas em quase todas as áreas da floresta, no entanto não foi possível a coleta dos nódulos desta espécie vegetal, visto que a mesma não apresentou nódulos em nenhuma das épocas de coleta. As demais espécies foram encontradas em regiões específicas.

O Inga lentiscifolia teve maior ocorrência em locais de mata fechada e maior teor de umidade, e Inga sp foi encontrado em locais fechados também, porém sem um alto teor de umidade.

Machaerium brasilienses estava localizada em uma região mais seca e com a presença de muitas pedras e serapilheira. Já Machaerium stipitatum teve ocorrência em regiões de mata mais fechada e com alta umidade no solo. Mimosa flocculosa está inserida na floresta via plantio em uma área delimitada, nessa área há presença de Mimosa scabrella, que também está inserida via plantio.

De acordo com a tabela 02 , pode-se verificar que os solos coletados ao redor da raiz das leguminosas estudadas possuem $\mathrm{pH}$ ácido, exceto o encontrado na

Tabela 02. Média das características químicas das amostras de solo rizosférico de cada leguminosa estudada.

\begin{tabular}{|c|c|c|c|c|c|c|c|c|}
\hline & Espécies & Ingá sp & $\begin{array}{c}\text { Ingá } \\
\text { lentiscifolia }\end{array}$ & $\begin{array}{c}\text { Machaerium } \\
\text { brasilienses }\end{array}$ & $\begin{array}{c}\text { Machaerium } \\
\text { spitatum }\end{array}$ & $\begin{array}{c}\text { Mimosa } \\
\text { flocculosa }\end{array}$ & $\begin{array}{l}\text { Mimosa } \\
\text { Scabrella } \\
\text { (Plantio) }\end{array}$ & $\begin{array}{l}\text { Mimosa } \\
\text { scabrella } \\
\text { (natural) }\end{array}$ \\
\hline & $\mathrm{pH}$ & 4.00 & 4.30 & 6.00 & 5.06 & 4.90 & 4.90 & 4.32 \\
\hline & índice de SMP & 4.40 & 5.30 & 6.32 & 5.84 & 5.48 & 5.48 & 5.00 \\
\hline \multirow{5}{*}{$\mathrm{cmolc} / \mathrm{dm}^{3}$} & $\mathrm{Ca}$ & 1.58 & 4.85 & 15.53 & 5.67 & 7.23 & 7.23 & 3.88 \\
\hline & $\mathrm{Mg}$ & 1.34 & 2.04 & 3.68 & 2.34 & 2.13 & 2.13 & 2.43 \\
\hline & $\mathrm{Al}$ & 4.09 & 2.08 & 0.01 & 0.36 & 0.60 & 0.60 & 2.06 \\
\hline & $\mathrm{H}+\mathrm{Al}$ & 27.78 & 10.78 & 3.15 & 5.76 & 8.02 & 8.02 & 15.12 \\
\hline & CTC & 7.19 & 9.21 & 20.13 & 8.70 & 10.14 & 10.14 & 9.32 \\
\hline \multirow{5}{*}{$\%$} & Alumínio & 58.38 & 25.70 & 0.06 & 5.39 & 6.45 & 6.45 & 24.00 \\
\hline & Bases & 10.24 & 41.05 & 86.12 & 48.49 & 54.13 & 54.13 & 35.11 \\
\hline & M.O & 4.90 & 6.46 & 12.90 & 4.40 & 6.12 & 6.12 & 5.70 \\
\hline & C.O & 2.84 & 3.75 & 7.48 & 2.55 & 3.55 & 3.55 & 3.31 \\
\hline & Argila & 74.80 & 47.40 & 36.83 & 45.80 & 70.33 & 70.33 & 61.40 \\
\hline \multirow{4}{*}{$\mathrm{mg} / \mathrm{dm}^{3}$} & $\mathbf{P}$ & 1.66 & 3.12 & 8.60 & 7.48 & 3.43 & 3.43 & 3.58 \\
\hline & $\mathrm{S}$ & $\mathrm{x}$ & $\mathrm{x}$ & $\mathrm{X}$ & $\mathrm{x}$ & $\mathrm{x}$ & $\mathrm{x}$ & $\mathrm{x}$ \\
\hline & $\mathrm{Na}$ & 10.00 & 7.20 & 14.16 & 24.40 & 6.67 & 6.67 & 10.40 \\
\hline & $\mathbf{K}$ & 68.40 & 95.00 & 356.16 & 125.00 & 67.17 & 67.17 & 368.20 \\
\hline cmolc/dm $\mathrm{dm}^{3}$ & СТC pH 7,0 & 30.88 & 17.92 & 23.26 & 14.09 & 17.55 & 17.55 & 22.38 \\
\hline \multirow{5}{*}{$\mathrm{mg} / \mathrm{dm}^{3}$} & $\mathrm{Cu}$ & $\mathrm{x}$ & $\mathrm{x}$ & $\mathrm{X}$ & $\mathrm{x}$ & $\mathrm{x}$ & $\mathrm{x}$ & $\mathrm{x}$ \\
\hline & $\mathrm{Zn}$ & $\mathrm{x}$ & $\mathrm{x}$ & $\mathrm{X}$ & $\mathrm{x}$ & $\mathrm{x}$ & $\mathrm{x}$ & $\mathrm{x}$ \\
\hline & B & $\mathrm{x}$ & $\mathrm{x}$ & $\mathrm{X}$ & $\mathrm{x}$ & $\mathrm{x}$ & $\mathrm{x}$ & $\mathrm{x}$ \\
\hline & $\mathrm{Fe}$ & $\mathrm{x}$ & $\mathrm{x}$ & $\mathrm{X}$ & $\mathrm{x}$ & $\mathrm{x}$ & $\mathrm{x}$ & $\mathrm{x}$ \\
\hline & $\mathrm{Mn}$ & $\mathrm{x}$ & $\mathrm{x}$ & $\mathrm{X}$ & $\mathrm{x}$ & $\mathrm{x}$ & $\mathrm{x}$ & $\mathrm{x}$ \\
\hline
\end{tabular}


espécie de Machaerium brasilienses que apresentou solo com $\mathrm{pH}$ ácido, mas próximo ao neutro.Este solo ainda apresentou índices maiores de SMP, cálcio, magnésio, CTC, bases, matéria orgânica, carbono orgânico e fósforo no solo quando comparado com os demais, salienta-se que, do local onde esta espécie foi encontrada existe área de plantio de milho, fator este que influência as condições encontradas no respectivo solo.

A caraterização dos nódulos ocorrentes nas espécies estudadas está descrita na tabela 03. Todas as espécies apresentaram os dois tipos de nódulos pelo menos em uma das estações.

Tabela 03. Tipos de nódulos encontrados nas espécies durante o período de inverno e primavera.

\begin{tabular}{c|c|c}
\hline Planta & $\begin{array}{c}\mathbf{N}^{\mathbf{o}} \mathbf{d e} \\
\text { isolados } \\
\text { inverno }\end{array}$ & $\begin{array}{c}\mathbf{N}^{\mathbf{o}} \mathbf{d e} \\
\text { isolados } \\
\text { verão }\end{array}$ \\
\hline Mimosa scabrella (natural) & 09 & 09 \\
Mimosa scabrella (plantio) & 04 & 03 \\
\hline Mimosa flocculosa & 05 & 09 \\
\hline Ingá sp. & 08 & 02 \\
\hline Ingá lentiscifolia & 02 & 07 \\
\hline Machaerium brasilienses & 04 & 04 \\
Machaerium stipitatum & 07 & 06 \\
\hline Total & $\mathbf{3 9}$ & $\mathbf{4 0}$ \\
\hline
\end{tabular}

Os isolados de bactérias fixadoras de nitrogênio foram separados em dois grupos, de acordo com o período de isolamento (inverno e primavera), agrupados com base nas características morfofisiológicas, obtendo-se assim, trinta e nove isolados durante a coleta de inverno e 40 na coleta de primavera, totalizando setenta e nove isolados (Tabela 04).

Tabela 04: Número de isolados por planta durante as estações de inverno e verão.

\begin{tabular}{c|c|c}
\hline Espécie & Inverno & Verão \\
\hline Mimosa scabrella (natural) & D e ND & ND \\
\hline Mimosa scabrella (plantio) & ND & D e ND \\
\hline Mimosa flocculosa & D e ND & ND \\
\hline Ingá sp & $\mathrm{D}$ & D e ND \\
\hline Ingá lentiscifolia & D e ND & ND \\
\hline Machaerium brasilienses & D e ND & D e ND \\
\hline Machaerium stipitatum & $\mathrm{D}$ & D \\
\hline Baubinia forficata & $\begin{array}{c}\text { Sem } \\
\text { nódulos }\end{array}$ & Sem nódulos \\
\hline
\end{tabular}

Legenda: D - determinado (esférico); ND - não determinado (cilíndrico/ramificado).

O maior número de isolados foi encontrado na Mimosa scabrella de ocorrência natural com um total de nove isolados em cada uma das épocas coletadas. A espécie
Ingá sp apresentou obteve um maior número de isolados durante o inverno, ao contrário das demais com ocorrência de mais isolados durante o período de verão. Como pode ser observado o maior número de isolados foi encontrado em Mimosa scabrella (natural) que estava estabelecida em local com $\mathrm{pH} 4,32$ e segundo maior teor de alumínio (tabela 02). Com base nas características morfofisiológicas das bactérias fixadoras de nitrogênio nodulantes (tabela 01) das espécies de leguminosas arbóreas descritas por Moreira; Huising; Bignell (2010) procedeu-se uma separação dos possíveis gêneros encontrados nos setenta e nove isolados das espécies de leguminosas arbóreas selecionadas para o estudo.

Como pode se observar na tabela 05 , grande parte dos isolados agregam-se nas características relacionadas ao gênero Burkholderia, totalizando vinte e nove isolados, seguido de dezenove isolados pertencentes aos gêneros de crescimento rápido Allorbizobium, Rhizobium, Sinorrbizorbium, Mezorbizobium aos quais não foi possível obter a separação, baseando-se somente nas características morfofisiológicas que foram correlacionadas, devido possuírem as mesmas características.

Os microrganismos foram caracterizados como Burkholderia por apresentarem alcalinização do meio de cultura, não podendo ser descartado ainda a existência de Burkholderia naqueles que apresentaram acidificação do meio de cultura, devido a sua versatilidade em relação a essa característica, porém estes foram agrupados em Rhizobium.

O gênero Bradhyrbizobium ficou constituído de doze isolados, seguido por Azorbizobium com onze isolados, quatro isolados dos quais possuem características referentes ao gênero Azorbizobium e Cupriavidus, onde não foi possível obter a diferenciação dos mesmos com base na taxa de crescimento. E por último, seis isolados não se agruparam nas características dos gêneros relatados por divergências entre o tamanho da colônia e o pH observado no meio de cultura.

Verificou-se por meio do agrupamento, que a nodulação mais frequente nas espécies de Mimosa ocorreu pelas bactérias do gênero Burkholderia, seguida dos gêneros de crescimento rápido Allorbizobium, Rhizobium, Sinorrbizorbium, Mezorbizobium. Constatou-se também a ocorrência do gênero Azorbizobium nas três espécies de Mimosa e um isolado com características de Bradbyrbizobium na espécie Mimosa flocculosa. Em Mimosa scabrella de ocorrência natural, constatou-se a presença de um Azorbizobium/Cupriavidus e de quatro isolados que não se encaixaram nas características para os gêneros de bactérias fixadoras de nitrogênio relacionados.

$\mathrm{Na}$ espécie Inga sp foram encontrados quatro isolados característicos de Burkholderia, três de Bradbyrbizobium, dois com características para o grupo de crescimento rápido, agregando Allorbizobium, Rhizobium, Sinorrbizorbium, Mezorbizobium e um isolado possuindo aspectos de Azorbizobium. Na espécie Inga lentiscifolia a 
Tabela 05. Agrupamento dos isolados obtidos, baseado nas características morfofisiológicas descritas por Moreira; Huising; Bignell (2010).

\begin{tabular}{|c|c|c|c|c|c|c|}
\hline Planta & $\begin{array}{c}\text { Allorhizobium } \\
\text { Rhizobium } \\
\text { Sinorrhizorbium } \\
\text { Mezorhizobium } \\
\text { Burkholderia }\end{array}$ & Bradyrhizobium & Azorhizobium & $\begin{array}{c}\text { Azorhizobium } \\
\text { Cupriavidus }\end{array}$ & Burkholderia & $\begin{array}{c}\text { Não se } \\
\text { encaixaram } \\
\text { em nenhum } \\
\text { grupo. } \\
1<\text { e ácido }\end{array}$ \\
\hline $\begin{array}{l}\text { Mimosa } \\
\text { scabrella } \\
\text { (natural) }\end{array}$ & $\begin{array}{l}01 \text { (bi31) } \\
45 \text { (bv82) }\end{array}$ & & $\begin{array}{l}05 \text { (bi35) } \\
42 \text { (bv79) } \\
44 \text { (bv81) }\end{array}$ & 50 (bv87) & $\begin{array}{l}02 \text { (bi32) } \\
03 \text { (bi33) } \\
07 \text { (bi37) } \\
43 \text { (bv80) } \\
46 \text { (bv83) } \\
47 \text { (bv84) } \\
48 \text { (bv85) } \\
78 \text { (bi29) }\end{array}$ & $\begin{array}{l}04 \text { (bi34) } \\
06 \text { (bi36) } \\
79 \text { (bi30) } \\
49 \text { (bv86) }\end{array}$ \\
\hline $\begin{array}{l}\text { Mimosa } \\
\text { scabrella } \\
\text { (plantio) }\end{array}$ & $\begin{array}{l}34 \text { (bpv 68) } \\
74 \text { (bpi24) }\end{array}$ & & 72 (bpi22) & & $\begin{array}{l}33 \text { (bpv67) } \\
35 \text { (bpv69) } \\
73 \text { (bpi23) } \\
75 \text { (bpi25) } \\
\end{array}$ & \\
\hline $\begin{array}{c}\text { Mimosa } \\
\text { flocculosa } \\
\text { (plantio) }\end{array}$ & $\begin{array}{l}26 \text { (bcv60) } \\
27 \text { (bcv61) } \\
28 \text { (bcv62) } \\
30 \text { (bcv64) } \\
70 \text { (bci17) }\end{array}$ & 31 (bcv65) & 68 (bci15) & & $\begin{array}{l}24 \text { (bcv58) } \\
25 \text { (bcv59) } \\
29 \text { (bcv63) } \\
32 \text { (bcv66) } \\
67 \text { (bci13) } \\
69 \text { (bci16) } \\
71 \text { (bci19) }\end{array}$ & \\
\hline Ingá sp & $\begin{array}{l}09(\operatorname{ci} 39) \\
13(\operatorname{ci} 45)\end{array}$ & $\begin{array}{l}08(\mathrm{ci} 38) \\
10(\mathrm{ci} 40) \\
52(\mathrm{cv} 89)\end{array}$ & 54 (ci41) & & $\begin{array}{l}1(\mathrm{ci} 43) \\
12(\mathrm{ci} 44) \\
51(\mathrm{cv} 88) \\
55(\mathrm{ci} 42) \\
\end{array}$ & \\
\hline $\begin{array}{c}\text { Ingá } \\
\text { lentiscifolia }\end{array}$ & $\begin{array}{l}38 \text { (av73) } \\
53 \text { (av70) } \\
76 \text { (ai27) }\end{array}$ & 39 (av74) & $40(\operatorname{av} 75)$ & & $\begin{array}{l}36 \text { (av71) } \\
37 \text { (av72) } \\
41 \text { (av76) } \\
77 \text { (ai28) } \\
\end{array}$ & \\
\hline $\begin{array}{c}\text { Machaerium } \\
\text { brasilienses }\end{array}$ & 64 (ii10) & $\begin{array}{l}20 \text { (iv52) } \\
21 \text { (iv53) } \\
23 \text { (iv57) } \\
63 \text { (ii09) } \\
66 \text { (ii12) } \\
\end{array}$ & & 22 (iv55) & 65 (ii11) & \\
\hline $\begin{array}{c}\text { Machaerium } \\
\text { stipitatum }\end{array}$ & $\begin{array}{l}15(\mathrm{xv} 47) \\
19(\mathrm{xv} 51) \\
57(\mathrm{xi02} \\
61(\mathrm{xi07})\end{array}$ & $\begin{array}{l}16(\mathrm{xv} 48) \\
56(\mathrm{xi} 01)\end{array}$ & $\begin{array}{l}17(\mathrm{xv} 49) \\
59(\mathrm{xi04})\end{array}$ & $\begin{array}{l}18(\mathrm{xv} 50) \\
58(\mathrm{xi03})\end{array}$ & 62 (xi08) & $\begin{array}{l}14(\text { xv46) } \\
60(\text { xi05) }\end{array}$ \\
\hline Total & 19 & 12 & 09 & 04 & 29 & 06 \\
\hline
\end{tabular}

predominância foi do grupo de crescimento rápido e de Burkholderia, apresentando ainda um isolado correspondente a Bradbyrbizobium e um pertencente a Azorbizobium. Pode-se verificar que ambos os grupos apresentaram ocorrência dos mesmos simbiontes, sendo que alguns com maior ocorrência em uma das espécies.

Nas espécies do gênero Inga também prevaleceram os nodulantes do gênero Burkholderia,
Rhizobium, Allorbizobium, Sinorrbizorbium e Mezorbizobium, com ocorrência dos gêneros Bradhyrbizobium e Azorbizobium. Dos isolados constituintes das espécies de Machaerium, 57,2 \% apresentaram crescimento lento a intermediário, com colônias puntiformes menores que $1 \mathrm{~mm}$, pouca produção de muco e alcalinizando o meio de cultura, características estas que se remetem aos gêneros Bradhyrbizobium, Azorbizobium ou Cupriavidus; 23,8 \% das colônias apresentaram-se circulares maiores que $1 \mathrm{~mm}$, com 
crescimento rápido média a muita produção de muco e acidificando o meio de cultura, o que se remetem a espécies dos gêneros Rhizobium, Allorbizobium, Sinorbizobium ou Mesorbizobium; 9,5\% dos isolados obtidos apresentaram características para o gênero Burkholderia, sendo colônias circulares maiores que $1 \mathrm{~mm}$, com produção de muco média a alta, crescimento rápido e alcalinização do meio de cultura. Ocorreu ainda na espécie de Machaerium stipitatum a presença $9,5 \%$ de isolados que diferenciaram suas características dos demais grupos, por apresentarem colônias menores que $1 \mathrm{~mm}$ e acidificarem o meio de cultura.
Com base na avaliação morfofisiológica dos isolados, avaliou-se o grau de polimorfismo obtido pelos grupos encontrados, fazendo uso das técnicas de RAPD e ERIC. Para a técnica de RAPD o melhor grau de polimorfismo para as bactérias fixadoras de nitrogênio foi com o uso do primer OPA-4, seguido do primer P-1251. Com base nesta avaliação o teste com os demais isolados foi realizado com o uso de OPA-4. Com relação ao perfil molecular apresentado diante do polimorfismo por RAPD, foi montado um dendrograma (figura 01) fundamentado no índice de similaridade de Jaccard, pelo método UPGMA, o qual permitiu a formação de seis grupos com uma similaridade de $50 \%$.



Figura 01. Dendrograma baseado no perfil molecular obtido na amplificação pelo método RAPD com o primer OPA-4; corte de $90 \%$ de similaridade.

Quando submetido ao corte de $90 \%$ de similaridade, obtém-se a presença de dezenove grupos. Dessa forma fica evidenciada a existência da diversidade entre as espécies, correlacionando seu grau de polimorfismo obtido pela amplificação no método RAPD.

Quando realizado o corte com base na similaridade de $50 \%$ entre os isolados, a técnica de ERIC apresentou oito grupos com perfis polimórficos similares, e submetendo a um corte baseado em $90 \%$ de similaridade é possível a observação de 18 grupos com a técnica de ERIC (figura 02).

Com um nível de $90 \%$ de similaridade a técnica de RAPD apresentou 19 grupos contra 18 grupos pela técnica de ERIC, demonstrando assim melhor separação entre os isolados do que esta última técnica. Considera-se ainda que ambas as técnicas foram eficientes quanto ao agrupamento dos isolados de acordo com o grau de polimorfismo.

Para a diferenciação dos isolados pelo método RFLP, com base na corrida em silico, foi selecionada a endonuclease Hinf para proceder os testes com os isolados, a qual obteve maiores diferenciações entre os gêneros.
Conforme os perfis moleculares obtidos, verificase que em todas as espécies de leguminosas arbóreas pesquisadas há a presença de bactérias do gênero Burkholderia, pois com o uso da endonuclease de restrição HinfI na corrida em silico, foi possível observar a presença de um perfil de bandas em $\approx 680$ e outro em $\approx 320$, correspondente ao gênero Burkholderia, sendo que os demais gêneros não apresentaram perfis parecidos a este.

Isolados de Mimosa scabrella (natural), Ingá sp, Machaerium brasilienses e Mimosa scabrella (plantio), apresentaram apenas dois perfis de bandas, sendo que nas demais espécies foi possível observar mais perfis. As bactérias isoladas dos nódulos de Mimosa flocculosa e Ingá lentiscifolia, obtiveram melhores resultados para a diferenciação, com a presença de mais perfis de bandas provenientes da clivagem com Hinf I.

Em comparação aos resultados encontrados na caracterização morfofisiológica, verificam-se algumas divergências nos resultados, pois quando foram analisados pelas características morfofisiológicas durante o isolamento, houve indicação de vários gêneros de bactérias nas espécies de leguminosas arbóreas, ao contrário do obtido na análise com a endonuclease de restrição. 
Figura 02. Dendrograma baseado no perfil molecular obtido na amplificação pelo método ERIC.

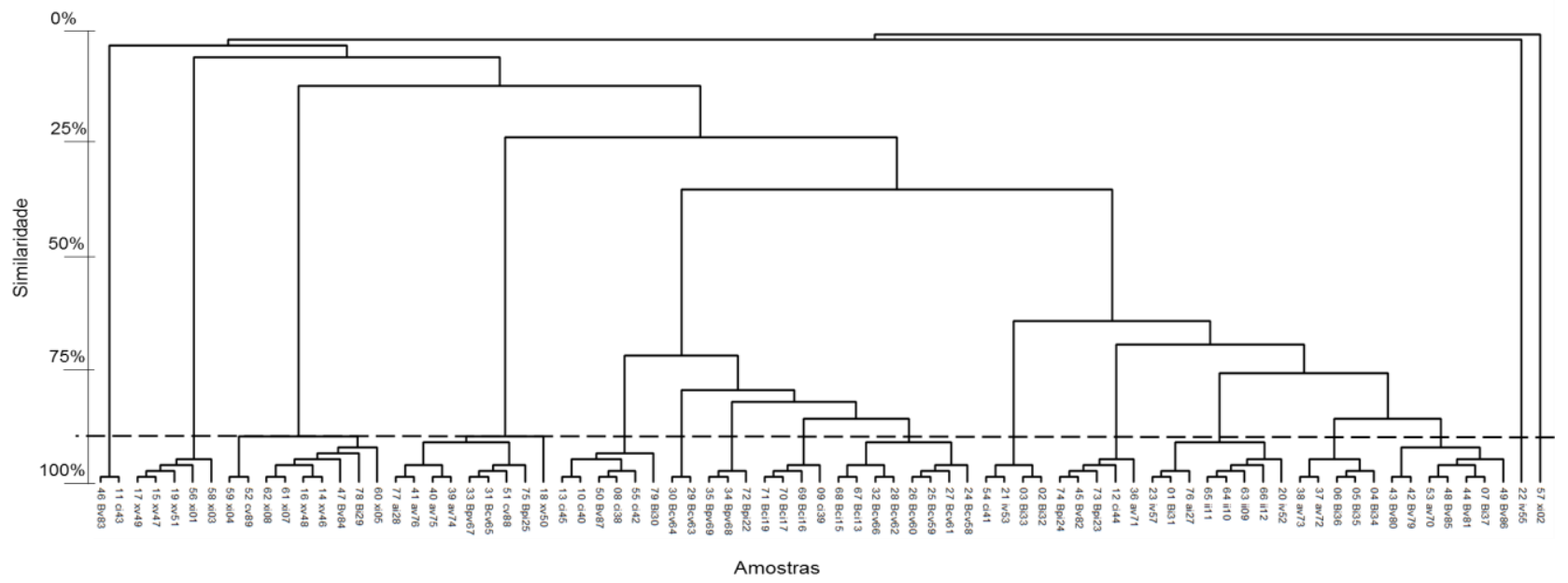

A maior ocorrência de microrganismos presentes em nódulos nas leguminosas selecionadas foi do gênero Burkholderia, porém com a endonuclease HinfI, não foi evidenciado a distinção dos demais grupos que estavam presentes nos nódulos. Isso é evidenciado pela comparação com as Machaerium, em que houve a predominância dos gêneros Bradhyrbizobium e Rhizobium pelas características morfofisiológicas (tabela 05).

Com base no agrupamento pelo índice de similaridade de Jaccard, usando o método UPGMA, obteve-se três grupos com $50 \%$ de similaridade provenientes da endonuclease de restrição Hinfl; com um índice de similaridade de $90 \%$, foi possível observar a presença de 54 grupos. O dendrograma com os grupos pode ser visualizado na figura 03 .

Os resultados dos géis provenientes da endonuclease HinfI (figura 03), mostram predominância de espécies do gênero Burkholderia, de acordo com os pares de base obtidos no mesmo. No dendrograma obtido pelo índice de similaridade de Jaccard, com um corte de $90 \%$ de similaridade, demonstrou uma alta diversidade de espécies dentro do gênero, comprovando resultado obtido quando observado o grau de polimorfismo pelas técnicas de RAPD e ERIC (figuras 01 e 02).

Figura 03. Dendrograma obtido a partir do perfil de bandas obtidas com a técnica de ARDRA utilizando a enzima $H$ infI

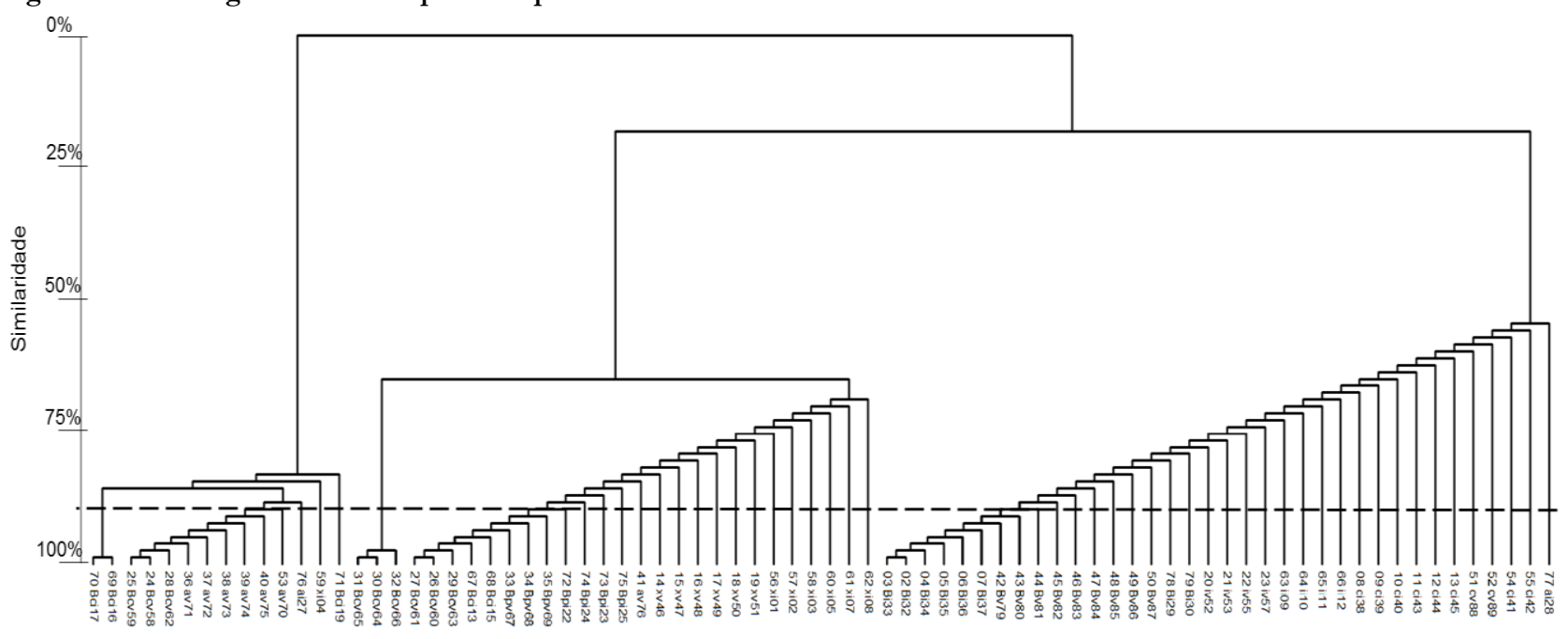

Amostras

Nota: baseado no perfil de banda obtido pela clivagem e com corte de $90 \%$ de similaridade. 
A ocorrência dos nódulos em espécies de leguminosas arbóreas pode ser do tipo determinados e não determinados, de acordo com Moreira (1994), os nódulos não determinados (ramificados) ocorrem nas três subfamílias existentes de leguminosas, enquanto os determinados (esféricos/nãoramificados) ocorrem predominantemente na subfamília Papilionoideae, sendo que há um maior tempo de atividade nos nódulos que se ramificam., quando comparado aos tipos de nódulos que não se ramificam, devido a característica efêmera como seu tecido fixador nos nódulos não ramificados. No presente trabalho, houve predominância de nódulos não determinados nas duas espécies pertencentes a subfamília Papilionoideae (Machaerium brasilienses e Machaerium stipitatum), assim como ocorreu a presença deste tipo de nódulos nas demais espécies, as quais pertencem às subfamílias Mimosoideae, correspondente às espécies Mimosa scabrella, Mimosa flocculosa, Ingá sp e Ingá lentiscifolia.

A acidez e toxicidade de alumínio são fatores comumente associados aos solos tropicais, e podem afetar as simbioses de leguminosas, porém nas simbioses de rizóbio com leguminosas arbóreas foi observada uma alta frequência de estirpes de rizóbio tolerantes a pH ácido. Uma maior frequência de estirpes tolerantes à acidez $(\mathrm{pH} 4,5)$ é encontrado em Caesalpinioideae com $85,7 \%$, em segundo está as Mimosoideae apresentando 48,8\% de estirpes tolerantes e menor frequência nas Papilionoideae com 28,8\% (MOREIRA, 1994).

Barberi et al. (1998) em trabalho sobre nodulação em leguminosas florestais também não verificaram a ocorrência de nodulação nas espécies de Baubinia sp. relatando ainda a baixa ocorrência de nodulação em espécies da família Caesalpinioideae, a qual a Baubinia sp pertence. De acordo com Moreira \& Siqueira (2006), a maioria das espécies de leguminosas não nodulíferas se encontram na família Caesalpinioideae.

Dobereiner (1984) relata que as espécies de leguminosas arbóreas são encontradas com nodulações abundantes apenas onde o equilíbrio foi perturbado ou em florestas de regeneração.

De acordo com Moreira (2008), as principais espécies de bactérias fixadoras de nitrogênio nodulantes em espécies do gênero Mimosa são Bradyrbizobium spp, Mesorbizobium loti, Rhizobium etli biovar mimosae, Burkholderia caribensis, Ralstonia taiwanensis, sendo que na Mimosa scabrella há maior ocorrência de Burkholderia mimosarium e na Mimosa flocculosa a maior ocorrência é de Burkholderia sp. Mudando assim os estudos que indicavam como melhor simbionte espécies do gênero Rhizobium.

De acordo com Faria; Uchôas (2007), em seus estudos sobre inoculantes eficientes na FBN, as recomendações para Mimosa scabrella se remetem as espécies Rhizobium sp, Bradyrbizobium sp e
Burkholderia mimosarum e para Mimosa flocculosa Rhizobium sp, Bradyrbizobium spp.

Segundo Rocha (2007), recentemente foram descobertas espécies de $\beta$-proteobactérias que formam nódulos funcionais em leguminosas tropicais, sendo que a família Burkolderiaceae pertence a estas $\beta$ proteobactérias e incluem estirpes de Burkholderia (originalmente isoladas de Machaerium lunatum) e uma estirpe de Ralstonia taiwanensis (isolada de Mimosa pudica), fato este que confirma a versatilidade de espécies de Mimosa, em formar simbioses com vários gêneros de bactérias fixadoras de nitrogênio.

Foram encontrados isolados com características semelhantes ao trabalho de Almeida et al. (2013) nas espécies de Inga, porém em proporções diferentes, Almeida et al. (2013), verificaram em seus estudos com cinco espécies de Inga, que 41,7\% das estirpes acidificavam o meio de cultura, 33,3\% alcalinizavam e $25 \%$ mantinham neutro o $\mathrm{pH}$ do meio de cultura, 67,7 \% das colônias apresentaram forma circular e 33,3\% forma irregular, em relação ao tempo de crescimento, 58,3 \% foi lento, 33,3\% intermediário e $8,3 \%$ rápido, a produção de muco variou de muito a abundante, cerca de $75 \%$ das colônias apresentaram elevação plana com superfície lisa. Dos isolados encontrados neste estudo, 42,1 \% apresentaram crescimento rápido, com colônias maior que $1 \mathrm{~mm}$, de forma circular e alcalinizaram o meio de cultura, 31,6\% possuíam crescimento intermediário a lento, colônias menores que $1 \mathrm{~mm}$ de forma puntiforme $\mathrm{e}$ alcalinizaram o meio de cultura. E apenas 26,3\% apresentaram crescimento rápido com colônias circulares maiores que $1 \mathrm{~mm}$ e acidificaram o meio de cultura.

Silva (2010) estudando a diversidade e eficiência de bactérias isoladas de nódulos de diferentes leguminosas, entre estas, várias espécies de Inga, sendo $100 \%$ dos isolados com crescimento rápido e a acidificação do meio de cultura, apresentando características para os gêneros Rhizobium, Sinorbizobium e Mersorbizobium. Em seu estudo ainda pode-se observar que em relação aos índices de diversidade, as espécies de Inga variaram de 0,24 a 1,49 diante de índice de Shannon. Santos (2010) em seu trabalho sobre a diversidade de bactérias em nódulos de Inga vera, constatou em sua primeira coleta, maior ocorrência de colônias de crescimento rápido com coloração amarela, brilhante, com bordas inteiras, produção de muco, correspondendo a $61 \%$ e menor parte correspondente a $23 \%$ das colônias com coloração branca, crescimento lento, forma circular com bordas lisas e com a capacidade de alcalinizar o meio, produzindo pouco ou nenhum muco. $\mathrm{Na}$ segunda coleta a predominância foi de bactérias de crescimento rápido, e na terceira coleta, a maioria das bactérias isoladas dos nódulos apresentou crescimento lento. 
Vários gêneros de leguminosas arbóreas das três subfamílias podem ser nodulados por estirpes de crescimento rápido e de crescimento lento e entre estes, o gênero Inga está inserido (MOREIRA, 1994). Nas espécies de Inga, de acordo com Moreira (2008) temos como principal simbionte Bradyrbhizobium japonicum. De acordo com Faria; Uchôas (2007), em seus estudos sobre inoculantes eficientes na FBN, as recomendações para Inga marginata se remetem a Bradyrbizobium sp, para a espécie de Inga thibaudiana recomenda-se Bradyrbizobium elkanii e Bradyrbizobium sp.

Barberi et al. (1998), estudando a nodulação em leguminosas florestais em viveiros de Minas Gerais, observaram a nodulação de estirpes com crescimento lento, colônias menores que $1 \mathrm{~mm}$ com colorações brancas de pouca a média produção de muco e que alcalinizavam o meio de cultura, se remetendo assim a espécies do gênero Bradbyrbizobium. E estirpes com características de crescimento rápido com colônias de coloração branca com pouca produção de muco e alcalinizando o meio de cultura, correlacionaram-se a espécies do gênero Burkholderia em duas espécies do gênero Machaerium.

Moulin et al. (2001) em seu trabalho sobre a nodulação em leguminosas por membros do grupo de $\beta$-proteobactérias, verificou que espécies do gênero Burkholderia são capazes de nodular espécies do gênero Machaerium e Vandamme et al. (2002) relata que Burkholderia phymatum foi isolada de Machaerium lunatum na Guiana Francesa. Moreira (2008) correlaciona a nodulação das espécies Burkbolderia sp, Bradyrbizobium japonicum, Rhizobium tropici e Burkholderia plymotum em espécies de Machaerium.

Com relação ao aparecimento de isolados com características divergentes das demais apresentadas para os oito gêneros descritos como nodulantes, Castelari (2010) relatou em seu trabalho sobre a diversidade de bactérias diazotróficas nodulíferas na Mata Atlântica, que diversos gêneros não apresentam bactérias normalmente consideradas nodulíferas de leguminosas, tais como Bacillus, Pseudomonas, Paenibacillus, sendo possível que estas bactérias representem endofíticos de nódulos. Possivelmente esse é o caso daquelas espécies que apresentaram características morfofisiológicas diferentes das que são encontradas nos gêneros descritos por Moreira; Huising; Bignell (2010). Chen et al. (2001) também relataram sobre novos isolados de fixadores de nitrogênio em espécies de Mimosa, sendo que foram encontradas espécies de Ralstonia taiwanensis nodulando a espécie. De acordo com Yang et al. (2006), novas estirpes de Burkholderia tendo sido isoladas de solo de floresta, e possuem capacidade de fixar nitrogênio atmosférico; estas foram identificadas como Burkholderia terrae.

Verifica-se que este gênero de bactéria tem se distribuído largamente entre as espécies de leguminosas, embora a pouco tempo não se tinham indícios de nodulação pelo gênero Burkholderia, atualmente são inúmeros os relatos, principalmente entre as espécies de Mimosa. Acredita-se que o uso de tecnologias mais precisas tenha auxiliado a identificação destes microrganismos fixadores de nitrogênio.

Conforme salientado durante a avaliação morfofisiológica, outra correlação a ser feita é a presença de microrganismos endofíticos nos nódulos de leguminosas arbóreas. Silva (2010), trabalhando com a diversidade de bactérias fixadoras de nitrogênio, correlacionou a presença de endofíticos nos nódulos de leguminosas, como Bacillus, Enterobacter, Pantoea, Klebsiella, Burkholderia e Pseudomonas. LI et al. (2008), em seus estudos também relatam a ocorrência de bactérias endofíticas em nódulos de leguminosas, como dos gêneros Burkbolderia, Bacillus, Pantoea, Serratia, Acinetobacter e Agrobacterium.

Ehrhardt-Brocardo et al. (2015), em estudos com isolados de nódulos de bracatinga, constataram a presença isolados com similaridades de $97 \%$ a $99 \%$ com as espécies Burkbolderia unamae, B.nodosa, B. caledonica, B. phytofirmans, B. bryophila. Ainda nesse trabalho, encontrou três isolados com $96 \%$ de similaridade ao gênero Pantoea e um isolado com $97 \%$ de similaridade ao gênero Pseudomonas, sendo esses endofíticos dos nódulos. Apenas um isolado teve $99 \%$ similaridade ao gênero Rhizobium.

Larguerre et al. (2001) utilizaram a metodologia de RFLP para avaliar a diversidade de estirpes de rizóbio; as análises mostraram, de uma maneira geral, a correlação com o espectro hospedeiro e independência do status taxonômico, já que os resultados não foram concordantes com os baseados na sequência do $16 \mathrm{~S}$ rDNA.

Di Cello et al. (1997) utilizaram a metodologia de RAPD para estudar mudanças na estrutura de populações de Burkholderia cepacia ao longo do crescimento de plantas de milho. Os autores identificaram um alto grau de polimorfismo, ou seja, alta diversidade genética entre os isolados. Larguerre et al. (2001) ressaltam sobre a transferência lateral entre espécies de rizóbio, que desempenham importante papel na diversidade e na estrutura de suas populações naturais. Com esse entendimento, pode-se supor que a capacidade de transferência vinculada ao alto grau de polimorfismo garante alta versatilidade ao gênero Burkholderia. Autores têm sugerido que algumas bactérias endofíticas de nódulos poderão evoluir para bactérias simbióticas por meio da transferência horizontal de genes simbióticos (LI et al., 2008; SHIRAISHI et al., 2010).

Algumas características do genoma dos microrganismos podem influenciar a grande versatilidade deles em responder ao meio, como por exemplo, a presença de replicons ou múltiplas sequências de inserção. De acordo com Dinis et al. (2008) na maioria das espécies de Burkholderia os 
genomas são grandes, o que lhes confere um dramático efeito sobre a estrutura cromossômica, o que talvez possa explicar a sua grande versatilidade.

Santos (2010), em estudo com bactérias de nódulos de Inga vera, constatou uma ampla diversidade genética dos formados não só por $\alpha$-proteobactérias, principalmente espécies de Bradyrbizobium, mas também por $\beta$-proteobactérias identificadas como sendo Burkholderia, gênero pela primeira vez relatado como associado aos nódulos desta leguminosa arbórea.

Luvizotto (2008), trabalhando com a caracterização fisiológica e molecular de Burkholderia associadas a raízes de cana-de-açúcar, relatou sobre a existência de 2 a 3 cromossomos nas espécies pertencentes ao gênero, além da capacidade de multireplicação, o que confere uma ampla plasticidade genômica e adaptabilidade metabólica às espécies. Salienta ainda que este gênero pode colonizar a rizosfera e ambientes endofíticos de uma vasta gama de plantas.

Uma análise filogenética de $N o d A$ e análise dos genes simbióticos nodC, nifH, e nifHD nos estudos de Shiraishi et al. (2010), sobre a nodulação por $\gamma$ proteobactérias e betaproteobactérias, detectaram a ocorrência de nodulação em Robinia pseudoacacia por Pseudomonas sp e a presença de genes simbióticos nesse gênero. Esses autores constataram, ainda, que o gene NodA apresentava alta relação genética entre estirpes de Pseudomonas sp, Agrobacterium sp, Burkholderia sp e Mesorbizobium loti isoladas do mesmo solo, o que indica uma possível ocorrência de transferência lateral de genes, indicando que as estirpes simbiontes adquiriram os genes de espécies rizobianas do solo.

Li et al. (2008) observaram semelhanças de 99\% nos genes nifH de Bradyrbizobium japonicum e das estirpes de Bacillus endofíticos encontrados, o que indicaram fortemente que a transferência horizontal de genes simbióticos entre as bactérias simbióticas e os endófitos.

Diniz et al. (2008), avaliando a genômica de Burkholdeira mallei e Burkholderia pseudomallei, considerou a transferência horizontal de genes como um mecanismo chave na evolução bacteriana, sendo que a transferência horizontal de genes pode ter um impacto mais imediato e significativo sobre o fenótipo do organismo quando comparado com processos mais lentos, tais como acúmulo de mutações no interior de genes individuais e a subsequente seleção por fenótipos vantajosos.

De acordo com Moreira (2010) o gênero Burkholderia possui alta diversidade, o que pode ser resultante da organização e do tamanho do seu genoma, já que o genoma de diferentes estirpes de Burkholderia cepacia possui de dois a quatro cromossomos de diferentes tamanhos e contém um grande número de sequências de inserção. Este número elevado de sequências de inserção pode ter um papel importante na habilidade desta bactéria de se adaptar a diferentes ambientes por meio de transferência genética e mutação.

O gênero Burkholderia possui alta versatilidade nutricional também, pois é capaz de crescer em mais de duzentos compostos orgânicos, dentre eles se encontram fontes de carbono incomuns como ácido azeláico e triptofano. Essa capacidade nutricional contribui para a habilidade competitiva frente a outros microrganismos em relação aos exsudados de plantas (LUVIZOTTOO, 2008).

Preocupa-se com a versatilidade existente no gênero Burkholderia em relação às interações ecológicas, já que a mesma, conforme demonstrado por outros autores, possui alta capacidade/habilidade de adaptação e transferência genética, considerando-se assim que o gênero poderia ter efeito ruim em relação aos demais gêneros de bactérias fixadoras de nitrogênio.

\section{CONCLUSÃO}

Considerando as condições de condução do estudo, entendemos que é possível concluir que:

No estudo analisado pela caracterização morfofisiológica, obteve-se a indicação de vários gêneros nodulando as espécies de leguminosas arbóreas encontradas, diferindo da caracterização genética. A análise do polimorfismo genético dentre os isolados mostrou alto grau de polimorfismo com as duas técnicas usadas, sendo RAPD com o primer OPA-4 e ERIC. Com o uso da endonuclease de restrição Hinfl, destinou para apenas um gênero de microrganismo nodulante das espécies de leguminosas arbóreas estudadas, predominando a nodulação do gênero Burkholderia, a qual foi correlacionado quanto a sua versatilidade nutricional e adaptativa, caracterizando assim o elevado grau de polimorfismo existente dentro do gênero.

\section{AGRADECIMENTOS}

A Universidade do Estado de Santa Catarina; Universidade Alto Vale do Rio do Peixe; Universidade do Oeste Catarinense; Empresa Brasileira de Pesquisa Agropecuária;

\section{REFERENCIAS}

ALMEIDA, Glória da Silva; et al. Capacidade de Nodulação em Inga sp. de Ocorrência na Amazônia Ocidental. Enciclopédia Biosfera, Centro Científico Conhecer - Goiânia, v.9, n.17; p. 2013. 
ARAÚJO, Ricardo S. Caracterização morfológica, fisiológica e bioquímica do rizóbio. In: HUNGRIA, Mariangela; ARAUJO, Ricardo S. Manual de métodos empregados em estudos de micorbiologia agrícola. Empresa Brasileira de Pesquisa Agropecuária. Brasília, 1994.

BARATTO, Cesar Milton; et al. Potential Use of Molecular-Typing Methods for the Identification and Characterization of Salmonella Enterica Serotypes Isolated in the Poultry Production Chain. Braqilian Journal of Poultry Science. Jul - Sept 2012/ v.14 / n.3 / 159-232.

BARBERI, Alexandre; et. al. Nodulação em Leguminosas Florestais em Viveiros no Sul de Minas Gerais. CERNE, V.4, N.1, p.145-153, 1998.

BERNARDI, Alini Zarpelon; Lipases com Potencial Aplicação para Produção de Biodiesel: Microrganismos Produtores e Expressão Heteróloga. Trabalho de conclusão de curso. Universidade do Oeste de Santa Catarina. 2012.

CALDATO, Silvana Lucia; LONGHI, Solon Jonas; FLOSS, Paulo Afonso. Estrutura populacional de Ocotea porosa (Lauraceae) em uma Floresta Ombrófila Mista, em Caçador (SC). Ciência Florestal. Santa Maria, 1999. v.9, n.1, p. 89-101.

CASTELARI, Aline Souza. Diversidade de bactérias diazotróficas noduliferas na Mata Atlântica. Dissertação. Escola Superior de Agricultura Luiz de Queiroz. Piracicaba, SP. 98p. 2010.

CHEN, W. M; et al. Ralstonia taiwanensis sp. nov., isolated from root nodules of Mimosa species and sputum of a cystic fibrosis patient. Int J Syst Evol Microbiol. 2001 Sep;51(Pt 5):1729-35.

DI CELLO, F; et al. Biodiversity of a Burkholderia cepacia Population Isolated from the Maize Rhizosphere at Different Plant Growth Stages. American Society for Microbiology. p. 4485-4493 Vol. 63, No. 11. Nov. 1997.

DINIZ, M.C. et al. Análise Genômica de Burkholderia mallei e Burkholderia pseudomallei: Dois Patógenos de Primeira Grandeza e de Genomas Surpreendentemente Complexos. Revista Brasileira de Higiene e Sanidade Animal, v. 2, n 1, p. $01-33,2008$.

DÔBEREINER, Jonanna. Nodulação e Fixação de Nitrogênio em Leguminosas Florestais. Pesq. agropec. bras., Brasília, 19 s/n: 83-90, jun. 1984.
EHRHARDT-BROCARDO, Natalia Carolina Moraes et al . Cultural, Morphological and Genetic Diversity of Diazotrophics Isolated from Nodules of Bracatinga. Rev. Arvore, Viçosa , v. 39, n. 5, p. 923933, out. 2015 .

FARIA, Sergio Miana de; UCHÔAS, Elisabeth da Silva. Indicação de estirpes de rizóbio eficientes na fixação biológica de nitrogênio para espécies de uso múltiplo, atualização ano base 2006. Seropédica, Embrapa Agrobiologia. 2007. 16p.

GROSS, Eduardo. Fixação biológica de nitrogênio em leguminosas arbóreas da Mata Atlântica e da Caatinga do estado da Bahia. Dissertação. Universidade Estadual de Santa Cruz (UESC). Ilhéus, 2010.

HERRERA, Hugo Alberto Hivera; et al. Análise Florística e Fitossociológica do Componente Arbóreo da Floresta Ombrófila Mista Presente na Reserva Florestal Embrapa/Epagri, Caçador, Sc - Brasil. FLORESTA, Curitiba, PR, v. 39, n. 3, p. 485-500, jul./set. 2009.

HUNGRIA, Mariangela. Coleta de nódulos e isolamento de rizóbio. In: HUNGRIA, Mariangela; ARAUJO, Ricardo S. Manual de métodos empregados em estudos de micorbiologia agrícola. Empresa Brasileira de Pesquisa Agropecuária. Brasília, 1994.

LARGUERRE, G; et al. Classification of rhizobia based on nodC and nifH gene analysis reveals a close phylogenetic relationship among Phaseolus vulgaris symbionts. Microbiology. 147, 981-993. 2001.

LI, J.H; et al. Genetics diversity and potential for promotion of plant growth detected in nodule endophytic bactéria of soybean growth in Heilongiiang province of China. Soil Biology Biochemestry. Oxford. v.40, n.1. p.238-246. Jan, 2008.

LUVIZOTTO, Danice Mazzer. Caracterização fisiológica e molecular de Burkholderia spp. Associadas ás raizes de cana-deaçúcar. Dissertação. Escola Superior Luiz de Queiroz. Piracicaba, 2008.

MACHADO, Sebastião do Amaral; et al. Funções de distribuição diamétrica em um fragmento de Floresta Ombrófila Mista. Ciência Rural, Santa Maria. v.39, n.8. p.2428-2434. Nov,2009.

MARMUR, Julius. A procedure for the isolation of deoxyrribonucleic acid from micro-organisms. J. Mol. Biol. 3:208, 1961. Departament of chemistry, Harvard University, Cambridge, MA. 
MAUNOURY, N; et al. Cell Biology of Nodule Infection and Development. In: DILWORTH, M.J. et al. Nitrogen-fixing Leguminous Symbioses. Cap. 6. Pág 153189. Institut des Sciences du Végétal.

MEYER, Leila et al. Fitossociologia do componente arbóreo/arbustivo da Floresta Ombrófila Mista em Santa Catarina. In: VIBRANS, Alexander Christian et al. Inventário Florístico Florestal de Santa Catarina: Floresta Ombrófila Mista. Blumenau: edifurb, 2013. v.3

MOULIN, L; et al. Nodulation of legumes by members of the beta-subclass of Proteobacteria. Nature. Jun/2001. 21;411(6840):948-50.

MOREIRA, Fátima M. S. Fixação Biológica do Nitrogênio em Espécies Arbóreas. In: ARAÚJO, Ricardo S; HUNGRIA, Mariângela. Microrganismos de importância agrícola. Empresa Brasileira de Pesquisa Agropecuária, Centro Nacional de Pesquisa de Arroz e Feijão: Centro Nacional de Pesquisa de Soja. - Brasília: EMBRAPA-SPI, 1994. 236p.

MOREIRA, Fátima Maria de Souza; SIQUEIRA, José Oswaldo. Microbiologia e Bioquímica do Solo. Lavras: Editora UFLA, 2006. $2^{a}$ ed. 729p.

MOREIRA, Fátima Maria de Souza. Bactérias fixadoras de nitrogênio que nodulam leguminosae. In: MOREIRA, Fátima Maria de Souza; SIQUEIRA, José Oswaldo; BRUSSAARD. Biodiversidade do solo em ecossitemas brasileiros. Lavras: ed. UFLA, 2008.

MOREIRA, Fatima Maria de Souza; et. al. Bactérias diazotróficas associativas: diversidade, ecologia e potencial de aplicações. Comunicata Scientiae. v.1(2): 7499, 2010.

MOREIRA, Fatima M. S.; HUISING, E. Jeroen; BIGNELL, David E. Manual de biologia dos solos tropicais: amostragem e caracterização da biodiversidade. Lavras: UFLA, 2010. 368p

NASCIMENTO, A. R. T.; LONGHI, S. J.; BRENA, D. A. Estrutura e padrões de distribuição espacial de espécies arbóreas em uma amostra de Floresta Ombrófila Mista em Nova Prata, RS. Ciência Florestal, Santa Maria, v. 11, n.1, p. 105-119, 2001.

PREMIERI, Silmar; et al. Diversidade morfológica de rizobactérias em nódulos de bracatinga (Mimosa scabrella) no estado de Santa Catarina. Seminário de Pesquisa, Extensão e Inovação do IFSC. 2013.
RINCÓN, Laura Emilia Cerón; GUTIÉRREZ, Fabio Aristizábal. Dinámica del ciclo del nitrógeno y fósforo em suelos. Revista Colombiana de Biotecnologia. v.XIV. n1. p.285-295. Julho, 2012.

ROCHA, Gisele Pinto. Bactérias Associativas e Simbiontes dos Nódulos de Arachis pintoi (LEGUMINOSAE). Dissertação de mestrado. Feira de Santana, BA. 2007.

SANTOS, Ellen Ribeiro Martins dos. Diversidade de bactérias em nódulos de Inga vera willd. (leguminosaemimosoideae) do sul da Babia. Universidade Estadual de Santa Cruz. Ilhéus - Bahia - Brasil Março de 2010

SILVA, Michele Aparecida Pereira da. Diversidade $e$ eficiência de bactérias isoladas de nódulos de diferentes leguminosas da região do Alto Solimões, AM. Lavras, UFLA. 2010. 82p.

SHIRAISHI, A.; et al. Nodulation in black locust by the Gammaproteobacteria Pseudomonas sp. and the Betaproteobacteria Burkholderia sp. Systematic and Applied Microbiology. v.33, p.269-274, 2010.

STRALIOTTOO, R.; RUMJANEK, N. G. Aplicação e evolução dos métodos moleculares para o estudo da biodiversidade do rizóbio. Seropédica - Rio de JaneiroRJ: Embrapa Agrobiologia, n.93, 58p, 1999.

TEDESCO, Marino José; et al. Análises de solo, plantas e outros materiais. $2^{\mathrm{a}}$ ed. Porto Alegre, RS. Departamento de solos, UFRGS. 1995.

VANDAMME, P; et al. Burkholderia tuberum sp. nov. and Burkholderia phymatum sp. nov., nodulate the roots of tropical legumes. Syst Appl Microbiol. 2002 Dec;25(4):507-12.

VIBRANS, Alexander Christian; et al. Floresta Ombrófila Mista. In: Inventário Florístico Florestal de Santa Catarina. V.3. Blumenau. Edifurb, 2013. 440p.

VIERA, Rosana Faria. Diversidade e taxonomia de rizobio. In: SILVEIRA, Adriana Parada Dias da; FREITAS, Sueli dos Santos. Microbiota do solo e Qualidade ambiental. Instituto Agronômico. Campinas, 2007.

YANG, H.C., Im, W.T., Kim, K.K., An, D.S., Lee, S.T. 2006. Burkholderia terrae sp. nov., isolated from a forest soil. International Journal of Systematic and Evolutionary Microbiology 56; 453-457. 